\section{TURISMO, HOTELARIA E \\ MEIO AMBIENTE \\ No Presente e no Futuro \\ uma Preocupação Permanente \\ ("Fit for the Future")}

\section{José Ruy Veloso Campos*} José Bento Desie**

RESUMO: Registro e reflexōes sobre o temário do $29^{\circ}$ Congresso Internacional da International Hotels Association (IHA), ocorrido em Estocolmo, Suécia, no mês de jullho de 1991.

UNITERMOS: Turismo: meio-ambiente; hotelaria, Meio ambiente: desenvolvimento de projetos. Hotelaria: preservação do meio ambiente.

ABSTRACT: Register and reflections on the themes discussed at the $29^{\prime \prime}$ International Congress of the International Hotels Association (IHA) held in Stockholm, Sweden, in July 1991

KEYWORDS: Tourism: environment; hotel industrv. Environment: hotel projects. Hotel industrv: environment; presenve.

\section{A QUESTÃO AMBIENTAL DEBATIDA}

\section{NO $29^{\circ}$ CONGRESSO DA IHA}

Sempre que se reúnem para discutir as questões ligadas ao turis mo e as decorrências de suas atividades no mundo, os representantes dos países em desenvolvimento - um eufemismo para a denominação de terceiro mundo que nos é dada pelos países

(") Professor universitário para as áreas de Turismo e Hotelaria. Gerente da área de Turismo e Hotelaria do SENAC para o Estado de São Paulo. Vice-Presidente da Associação Brasileira dos Dirigentes de Escolas de Hotelaria.

End. para corresp.: Rua Dr. Vila Nova. 228. $6^{\circ}$ andar 01222 -São Paulo - SP - Brasil.

(**) Bacharel em Turismo pela Faculdade Itero Americana. Gerente do SENAC CEATEL - Centro de Estudos de Administração Hoteleira e Turismo. Diretor do Instituto Superior de Hotelaria e Turismo do SENAC de São Paulo. End. para corresp.: Rua São Vicente, 245 - 01314 - São Paulo - SP - Brasil. desenvolvidos - tendem a assumir que a questão do turismo começa a ficar irrelevante diante das grandes necessidades sociais nos países que compõem esse bloco e que, diga-se de passagem, não são poucos.

Não restam dúvidas sobre as grandes necessidades econômicas e sociais do bloco terceiromundista onde a saúde e a educação - por exemplo - são tratados com descaso e grandes somas são canalizadas para grandes obras de impacto político e que - também não raro - encobrem manobras inconfessáveis

Um fato concreto, porém, é que o turismo é para muitos desses países uma das soluções para a entrada de divisas e geração de empregos no mercado interno. Tome-se como exemplo o Caribe, alguns países africanos, a Índia e a Malásia.

O que faz desses países uma atração turística para os povos do primeiro mundo é o exotismo de sua gente e de suas paisagens. Mais do que isso, os povos de países ditos "civilizados" precisam oxigenar seus pulmões e suas cabeças em lugares onde o espectro do progresso predatório ainda não chegou.

Até quando esses países serão conhecidos por suas belezas naturais é uma outra história que vem preocupando cientistas, pessoas, e às vezes, até autoridades.

Do ponto de vista da indústria turística em geral, muitas são as providências já tomadas em diversos países no sentido de diminuir o impacto dos empreendimentos e da movimentação gerada por estes no meio ambiente. O primeiro mundo tem tido essa preocupação, sobretudo depois que se deu conta de que tudo o que tinha em seu "seio" foi por ele mesmo destruído. Resta agora passear no quintal, que é o terceiro mundo. E para isso ele tem que estar conservado.

O Brasil encaixou-se nesse tipo de esforço quando, na nova Constituição, aprovou o RIMA - Relatório de Impacto no Meio Ambiente que deverá, em princípio, controlar a desenfreada corrida para o investimento turístico em regiões desprotegidas e até mesmo nos chamados "santuários".

A questão ambiental tem ensejado revisões comportamentais dos povos de diversos pontos da terra, sobretudo da grande aldeia dos chamados "povos urbanos", essa massa que hoje habita as metrópoles.

É por conta das questões ambientais, por exemplo, que se revê hoje a prosaica conduta de não atirar papéis ao chão e - em conseqüência disso - provocar o entupimento das galerias pluviais, uma das causas das enchentes urbanas. 
O turismo certamente envolve todos esses aspectos já que tanto os serviços prestados pelos "trades", como os consumidores na ponta final dessas ações, podem ser os veículos predatórios ou as vítimas de uma desorganização nesse sentido.

Diversos braços desse "trade" têm procurado soluçōes para melhor adequar os serviços turísticos à preservação do meio ambiente tirando partido disso tanto do ponto de vista do serviço efetivamente oferecido como do ponto de vista de sua imagem institucional. Nesse aspecto, a hotelaria internacional tem se movimentado bastante como ficou claro no $29^{\circ}$ Congresso da International Hotel Association (IHA), realizado em Estocolmo, no mês de julho de 1991.

Naquele evento, profissionais de diversas partes do mundo levantaram questōes relevantes às quais os hotéis devem estar atentos quando da efetivação de seus projetos de construção, reforma e novos serviços oferecidos aos hóspedes.

Diversos "workshops" discutiram assuntos ligados ao tema, sendo uma preocupação para as companhias em diversos países que já têm leis severas para controlar os danos à natureza.

Nesse aspecto, por exemplo, Andrew Little da Field Fisher Waterhouse, Londres, que conduziu um "workshop" sobre Construção e Desenvolvimento de Hotéis lembrou o trabalho da Comissão Européia que estudou e propôs um programa de ação para o meio ambiente desde 1972. Esta comissão adotou diretrizes para o meio ambiente e as distribuiu para que cada país europeu as adaptasse de acordo com suas legislações. Os assuntos envolviam água, sobras, ar, químicas, odores e vida selvagem.

$\mathrm{Na}$ verdade, a proposta européia não difere muito da proposta brasileira do RIMA, já que cobre desde os projetos classificados como de alto risco (usinas atômicas, refinarias de óleo e indústrias poluidoras em geral) até os projetos de lazer. Estes, por sua vez, devem prever com cuidado as compras de alimentos, móveis etc., para não levarem à mesa ou integrarem aos seus mobiliários produtos oriundos de países que não respeitam o meio ambiente e, conseqüentemente, podem oferecer produtos contaminados ou, ainda, causar muitos danos à natureza no que diz respeito a produtos manufaturados.

\section{INTERIORES \& MADEIRAS}

A preocupação com o meio ambiente está também nos projetos de "design" de interiores cujas diretrizes se aplicam não só a hotéis mas a qualquer tipo de construção que se queira desenvolver no mundo hoje.
A grande defesa do escritório de arquitetura e "design" de interiores de Londres, Wilson Gregory Aeberhard, foi a madeira. Eles citam os países do terceiro mundo como os últimos e únicos em condiçōes de preservar o pouco que resta de grandes matas de madeiras de lei. Indonésia, Quênia e Brasil são citados entre os que ainda guardam algumas espécies raras em suas florestas.

O escritório aconselha a restrição do uso de madeira de lei e propõe sua substituição por outros produtos ou madeiras mais comuns submetidas a tratamento.

Além disso, os arquitetos divulgaram uma lista de quase 30 diferentes madeiras (o Brasil está presente com três: pau marfim, peroba vermelha e madeira rosa), cujo uso deve ser evitado, bem como outras que podem ser utilizadas ainda livremente.

Outro enfoque do escritório de arquitetura inglesa é o uso de pedras já chamadas de "material verde de construção", que é como se denominam na Europa os materiais que não apresentam contra-indicações do ponto-de-vista-ambiental.

Além das inúmeras vantagens decorativas, as pedras oferecem maior resistência e podem ser protegidas contra a degradação prematura.

Certamente que todos os aspectos abordados pelos arquitetos estão diretamente relacionados com o custo das construções, da decoração e da reposição de móveis e objetos utilizados nos hotéis e outros estabelecimentos. Buscando formar os "Eco-educados", o escritório Aeberhard procura trabalhar também a consciência de sua clientela mostrando às grandes companhias que, mais do que uma imagem institucional e o charme de uma preocupação com o momento da "descida para a hecatombe ambiental", é preciso que tenham consciência de que o seu futuro no mercado e a qualidade de vida de seus descendentes podem estar ameaçadas se não souberem, hoje, controlar situações ainda controláveis.

Outro aspecto interessante e de grande peso para o universo hoteleiro no evento de Estocolmo foi a participação de Joseph Wheeler, diretor do programa de integração da ONU para a conferência sobre Meio Ambiente e Desenvolvimento, traduzida para o Brasil como ECO-92.

Wheeler lembrou que em 1972, em Estocolmo, a ONU tratava de uma conferência sobre o meio ambiente humano e lembrava aos presentes que a questão ambiental teria que ser a pauta maior de sua agenda em pouco tempo. 
O diretor da ONU tratou de questões como o aumento de temperatura da terra, das doenças da agricultura, das questões de distribuição de renda e registrou que na ECO-92, no Rio, os assuntos mais discutidos deverão ser a temperatura do globo e a biodiversidade esperando-se que o índice de queimadas em todo o mundo tenha baixado consideravelmente.

Segundo Wheeler, por volta de 2025 , seis em cada dez pessoas vai viver nas cidades e quatro de cada cinco habitantes das cidades estarão em países em desenvolvimento onde os recursos básicos serão insuficientes para os serviços necessários.

Nesse aspecto a energia é questão vital. As edificações terão que sofrer arranjos vitais para poupar energia, tanto quanto os meios de transporte terão que passar por soluçōes mais adequadas tanto para poupar energia (leia-se petróleo), quanto para dar espaço e poluir menos.

\section{3 "GREEN IS GOOD FOR BUSINESS"}

A melhor definição para a linguagem lucrativa - e lucrar é justo e saudável, desde que não prejudique a natureza e tampouco o homem dos empreendedores hoteleiros e da construção civil partiu de um americano do Texas.

Ray Hankamer Junior, da Southwest Hotel de Houston, Texas, faz a constatação de que as grandes cidades dos diversos países com raízes históricas ou exóticas (quase sempre no terceiro mundo) deixam-se poluir pelos automóveis, pelos esgotos, pelo lixo e pelas construçōes pouco apropriadas. Isso leva as pessoas a buscarem hospedagem, mesmo quando em viagem, fora do perímetro urbano, passando pela cidade por poucos minutos; só mesmo para ver algum marco histórico num "sight-seeing".

Hankamer evocou os cruzeiros marítimos para lembrar aos hoteleiros que o balanço do navio não é melhor do que o conforto dos grandes quartos em terra firme mas têm oferecido, sobretudo, a possibilidade de ar puro, com razoável qualidade e garantia.

Sua proposta é simples e quase prosaica: cada hoteleiro deve plantar uma árvore por unidade habitacional do seu hotel.

Por que árvores?

Porque as árvores dão aos homens abrigo, material para construções, mobiliário, defesa, papel, transporte, utensílios para alimentação, comida, remédios e muito mais desde que a história começou.
Por iniciativa da cadeia Southwest Hotes, foram plantadas, em Houston, Texas, 1.500 árvores, e no final de junho, ele, Hankamer Junior, foi convidado para plantar a primeira de 4.000 árvores no estado mexicano de Guanajuato, que ele considera o primeiro degrau para o plantio de árvores em todos os estados mexicanos.

A mensagem do texano é a de que os hoteleiros devem pensar verde.

Se a empresa pensar verde, acredita ele, as comunidades vão gostar disso, os empregados vão admirar a empresa e, o melhor de tudo, seus hóspedes (e os futuros hóspedes) estarão sensibilizados por uma ação institucional ao gosto do momento e que deve resultar num bom recurso para o futuro.

O texano arrematou sua palestra com um chavão ao gosto do bom capitalismo: Verde é bom para os negócios.

Mais do que o negócio numa perspectiva mais imediatista, o "trade" turístico começa a perceber que os seus negócios poderão durar poucas gerações se a questảo do meio ambiente não for encaminhada satisfatoriamente.

A curto prazo acabam a imagem e o peso da demanda. A longo prazo extingue-se o negócio e acabam as empresas.

Preparar-se para o futuro é, portanto, uma questão de cidadania que deve estar embutida nas ações das empresas, sobretudo aquelas que vendem serviços de lazer e que tratam de um produto tão intangível para esse produto tão precioso que é o homem.

\section{CONSIDERAÇÕES FINAIS}

Complementando as indicaçōes e providências que os anais desse evento em Estocolmo registraram, levanta-se a questão do Recurso Humano. Enfatizou-se que o sucesso das iniciativas visando a preservação ambiental tem um único grande sustentáculo que é a verdadeira pré-disposição do ser humano em concretizá-las. Nesta questão a responsabilidade das empresas que compõem a malha turística mundial é inquestionável, pois o despertar da consciência e da postura preservacionista só pode se dar no interior de cada uma dessas empresas.

Os colaboradores e profissionais que atuam principalmente nos estabelecimentos hoteleiros, devem ter acesso a programas de treinamento profissional e desenvolvimento pessoal, que visem a identificação, análise e absorsão de práticas relativas à preservação do meio ambiente. 
Do ponto de vista comercial, se a empresa puder contar em seus quadros com recursos humanos atentos a questōes de uso racional de energia, reaproveitamento de materiais e prevenção de desperdícios, certamente haverá um reflexo positivo na relação receita/despesa; por outro lado, do ponto de vista institucional estes conceitos também poderão ser transmitidos, por exemplo, aos hóspedes que freqüentam um estabelecimento hoteleiro, transformando-o não só em uma empresa preocupada internamente com essa grande questão mundial, como também em um agente ativo de conscientização dos clientes que por ela são atendidos. 